\title{
Severe and prolonged febrile agranulocytosis under thyrosol
}

\author{
Mihaela Ionică', Roxana Geantă ${ }^{*}$, Șerban Benea', Bogdana Manu', Alina Cozma', Mihai Olariu', Olga Dorobăț', \\ Cleo Roşculeț ${ }^{1}$, Ramona Zamfir ${ }^{1}$, Adrian Miron, Elisabeta Benea ${ }^{1}$ \\ From The 10th Edition of the Scientific Days of the National Institute for Infectious Diseases "Prof Dr Matei \\ Bals" \\ Bucharest, Romania. 15-17 October 2014
}

\section{Background}

It is well known that patients with severe neutropenia are susceptible to bacterial infections, which may become lifethreatening. This hematologic disorder frequently occurs as an adverse effect of certain drug therapies. One of them, currently encountered in practice, is therapy with antithyroid drugs. An infective source is identified in average in $20-30 \%$ of febrile neutropenia episodes. Often the only infection proof is bacteremia, documented in 10-25\% of patients.

\section{Case report}

We report the case of a patient known with BasedowGraves disease, who developed a febrile agranulocytosis under thyrosol, and in which Pseudomonas aeruginosa was isolated from blood culture. Although the antibiotic treatment proved efficient and the patient recovered the neutropenia due to granulocyte colony-stimulating factor, the initial evolution was unfavorable, due to the impossibility of continuing antithyroid treatment and due to a heart rhythm disorder that appeared subsequently, on the patient's background of mitral and aortic regurgitation. During hospitalization, a transfer to the intensive care department was necessary.

After the remission of agranulocytosis, the patient underwent total thyroidectomy, because of an absolute contraindication of ever using thyrosol therapy. At 3 months of follow-up, the patient is on thyroid substitution, and is stable.

\section{Conclusion}

Despite an initially poor prognosis, the eventual evolution was favorable, through interdisciplinary cooperation between infectious diseases, endocrinology, hematology, cardiology, intensive care and surgery.

\section{Consent}

Written informed consent was obtained from the patient for publication of this Case report and any accompanying images. A copy of the written consent is available for review by the Editor of this journal.

\section{Authors' details}

${ }^{1}$ National Institute for Infectious Diseases "Prof. Dr. Matei Balş", Bucharest, Romania. ${ }^{2}$ Elias University Emergency Hospital, Bucharest, Romania.

Published: 15 October 2014

doi:10.1186/1471-2334-14-S7-P96

Cite this article as: lonică et al:: Severe and prolonged febrile

agranulocytosis under thyrosol. BMC Infectious Diseases 2014 14(Suppl 7):P96.

Submit your next manuscript to BioMed Central and take full advantage of:

- Convenient online submission

- Thorough peer review

- No space constraints or color figure charges

- Immediate publication on acceptance

- Inclusion in PubMed, CAS, Scopus and Google Scholar

- Research which is freely available for redistribution

"National Institute for Infectious Diseases "Prof. Dr. Matei Balş", Bucharest, Romania

Full list of author information is available at the end of the article 